\section{Factors Influencing Sri Lankan Family Size: With Special Reference to Colombo District}

\author{
Prasangi, R.G.D. ${ }^{1,}{ }^{*}$, Jagoda, D.J. ${ }^{1}$ and Rathnayake, R.M.L. ${ }^{1}$ \\ ${ }^{1}$ Department of Economics and Statistics, Sabaragamuwa University of Sri Lanka, Belihuloya, 70140, Sri Lanka.
}

Sri Lanka Journal of Social Sciences and Humanities Volume 1 Issue 2, August 2021: 99-107 ISSN: 2773 692X (Online), 27736911 (Print) Copyright: (C) 2021 The Author(s)

Published by Faculty of Social Sciences and Languages, Sabaragamuwa University of Sri Lanka Website: https://www.sab.ac.lk/sljssh DOI: http://doi.org/10.4038/sljssh.v1i2.42

Received: 30 November, 2020, Revised: 26 April, 2021, Accepted: 27 June, 2021.

How to Cite this Article: Prasangi, R.G.D., Jagoda, D.J. and Rathnayake, R.M.L. (2021). Factors influencing Sri Lankan family size: With special reference to Colombo District. Sri Lanka Journal of Social Sciences and Humanities, 1(2), 99-107.

\begin{abstract}
Family is the most basic unit of human society which is a collection of people bound together by relations. The fertility rate refers to the average number of children a woman can have during her child-bearing period. According to United Nations World Population Prospects statistics, the Sri Lankan fertility rate was 2.177 , and the fertility growth rate was -0.77 percent in 2020 . Therefore, the main objective of this study was to examine factors that affect Sri Lankan family size. Using the multi-stage cluster sampling method, 350 families were selected for the survey of which 272 from those residing in the Colombo district were gathered via structured questionnaires and telephone conversation. The gathered data was analyzed using Statistical Package for Social Science (SPSS) software along with the Binary Logistic Regression model to achieve the main objective. A woman's age of marriage, inclinations to use contraceptive methods, and the increase in natural abortions were identified as the main factors determining the number of children in a Sri Lankan family. The number of children in the household decreases as a woman's age of marriage is postponed. Similarly, women who use contraceptive methods have fewer children than those who don't. The serious problem of increasing natural abortions also influences the number of children in a household on the fact that the number of children of a woman who faced at least one abortion shows a significant decrease compared to women who hadn't faced any at all.
\end{abstract}

Keywords: Average Number of Children in Household, Binary Logistic Regression, Total Children Ever Born

\section{INTRODUCTION}

The family is considered the basic unit of society because of its role in generating resources of human capital and its ability to influence the behavior of individuals, households, and communities (Sriram, 1993). The English word 'Family' is derived from the Latin term 'Familia' which means a collection of simple relatives. Every person in the world gets their first membership in the family they are born in. A society is formed by the combination of a group of families. Thus, the basic foundation of all social relationships is laid through this 'family' unit. The concept of family was defined under three categories: structure of the family, work direction, and transactional process (Noller and Fitzpatrick, 1993). A family is the activating unit for the socialization and nurturing of children (Lerner and Spanier, 1978). In contemporary society, a family could be defined as small household units. Still, it is very difficult to properly define what a family is due to reasons such as a family's widespread, the changes over time, and its scope of expansion. The corporation among the individuals within such a family is the most fundamental corporation that can be seen in human society.

With the advent of language and technology, mankind began to develop rapidly and their outlook on the term 'family' also gradually changed. The structure of families in the present is drastically different from those in the past when extended families lived as tribes for several generations. This was caused by the industrial revolution in the West which in turn impacted the politics, education, and culture of 20th century Sri Lanka. Family affairs, which was a product consumption unit also became complicated. Thus, along with the demographic changes in the country, the traditional families underwent major changes and steered towards the small family concept. Some of the main reasons behind this change are increased age of marriage, abortion rates, family planning practices, divorce rates, time spent on education, female employment, etc.

The fertility rate is an indicator of the average number of children in a household and also refers to the average number of children a woman can have during her child-bearing period. The total fertility rate is calculated as the sum of the age-specific birth rates (5-year age groups between 10 and 49) for female residents who are lived in a specified geographic area during a specified time multiplied by five. Fertility is one aspect of demographic dynamics that contributes significantly to the size and structure of the population over time. Fertility can be identified as a woman's actual performance of reproduction (Dana, 2018). Cleland and Wilson (1987) stated that family size is a good measure of a person's fertility. It is an indication of the people's intent to have either a small or large family.

Today, in almost every country, the number of children in a household has dropped significantly. This is particularly notable in developing countries and developed countries while in contrast, non-industrialized countries do not show a significant decline in the number of children per family. While

* Corresponding author: Tel.: +94 (71) 5822213; Email: dhanuprasangi@gmail.com

(iD) https://orcid.org/0000-0002-2076-4302 
fertility in different countries of the world shows diversity, differences in fertility between regions of the same country are also common.

United Nations World Population Prospects statistics show that the 2020 global fertility is below 2.5. Its value is 2.448 . This means that globally, the average number of children per woman is currently less than three. In addition, the global fertility rate in comparison to 2019 has decreased by 0.41 percent in 2020. This reveals that a higher fertility rate of 2.458 was seen in 2019 with the average number of children per woman being three.

According to the total fertility rate, Sri Lanka ranks at 97th place in 2017 country rankings. United Nations World Population Prospects statistics reveal the Sri Lankan fertility rate as 2.177 in 2020 . This shows that the average number of children born to a woman is around two during her child-bearing period. This is a vast decline in fertility rate in the country compared to the fertility rate of 5.8 in 1950 when a woman had about six children on average. Accordingly, the number of children per household declines for a variety of reasons, and as such, the fertility growth rate has been negative for many years. The 2020 fertility growth rate is -0.77 percent, which indicates that the fertility rate in 2019 has fallen by 0.77 percent until 2020

The main consequence of the decrease in the number of children per household was the increase in the aging population. A large aging population is dependent on a small younger population. As such, the ability to care for the aging population is also minimized. The mortality rate also shows a gradual increase as the adult population increases. As the elderly population grows, the government will have to pay much more for pensions, social security funds, and elderly healthcare. Similarly, with fewer children in the household, the labor force of a country is decreasing. Decrease in the workforce results in degradation of human capital and reduction of productivity. Due to these adverse impacts, the drop in the number of children per household has been identified as a problem in Sri Lanka and globally.

Social changes cannot be prevented and the past cannot be reversed. It is necessary to adapt the good qualities of the past to better suit the present society. The main purpose of this study is to identify the factors influencing Sri Lankan family size.

Specific objectives

- To identify the demographic factors which have a significant effect on Sri Lankan family size.

- To identify the socio-economic factors which have a significant effect on Sri Lankan family size.

- To identify the cultural factors which have a significant effect on Sri Lankan family size.

\section{LITERATURE REVIEW}

Based on the economic approach of the new household concept, Becker (1960) introduced two theories about the total fertility rate. The first one was based on time allocation and explained that more time should be allocated for children than other goods of consumption. The second one was based on the quantity-quality trade-off preference and explained that households should consider suitable fertility relative to expenditure on children and income.

Family size refers to the number of children a married couple will have during their childbearing period. Dibaba and Mitike (2016) stated that family size is the total number of children a woman can give birth to during her fertile period.
The size of a family plays an important role not only for the country but also for the well-being and health care of the family and society of individuals (Arthur, 2005). The size of a family depends only on the needs of the husband and wife. Some create a small family of their own while others create a large family of their choosing. The desired size of a family is an expression of fertility intentions (Harbour, 2011).

The theory formulated by Richard Easterlin is considered to be the most popular theory of fertility. He thought that patterns of fertility followed a 40-year cycle. He pointed out that the young adult population in any 20 years denoted the birth rate of the previous 20 years. He says people with low birth rates have easier access to the job market and better pay and faster career advancement. It also states that people with a higher birth rate receive lower economic benefits. The number of young adults entered into the working population depends on the number of births in any generation. The effect of deaths and migration do not vary from generation to generation. During 1945 and 1960 there was a shortage of young workers and competition in the job market was limited. So, their lifestyle, marriage, and fertility increased. But, by the 1970s, the number of young workers had increased job market competition was created. So, marriage and fertility gradually declined. He further pointed out that determine marriage and fertility depends on a couple's earning power. He stated that the higher the relative income, the less economic pressure a couple has, so they can make a free decision about marriage and fertility.

Diane Macunovich trusts that the primary influence of collective size is the relative earnings of young people to older members of the workforce. She cites only inexperienced young workers as the main reason for the relative decline in wages, rather than experienced older workers. Theory of Easterlin's, based solely on men's earnings, where he does not consider the role of women. But she considers that a woman has material desires. From 1960 to the 80s, women believed that they could not achieve their prosperity by relying on men's earning. It is therefore accepted that women should be included in the labor force. So, they were motivated to get a higher education. As a result, marriages are delay, and fertility rates fall. Through her model, she measured the association between relative earns and wages of women. She points out that an increase in men's income leads to an increase in fertility, while an increase in women's income leads to a decrease in fertility. Also, increasing female wages during periods of low male income has a positive effect on fertility as it leads to an increase in overall income. This principle assumes that there is a one-year delay between relative earns and fertility. This is because fertility does no change as soon as income changes. That is, they need time to decide if they are financially ready to have a child.

This model of W. Butz and M. Ward considers about two variables. That is the income of a family and the women's time opportunity cost. This theory assumes that high-income families have more children when other factors are the same. Also, they state that women with high income have fewer children because the opportunity costs for childbirth are higher. Factors influencing the participation of women in the workforce also influence the decision regarding the number of children women have. They say that make up more than one-third of all births and that young women are responsible for the entire population. It also suggests that there is a negative association between fertility and the employment of females. They believe that in the 1920san increase in women's wages led to a decreased fertility and by 
1935 a decrease in women's wages led to an increase in fertility. With this model, they explain fertility patterns. In their model, they explained that future fertility would continue to decline if women's wages and employment opportunities continued to rise.

Through John Ermisch's theory, he explains that the main factor of fertility is not the movement of relative income and the main reason is the demand for female workers. He believes that the main factor that determines the size of a family is whether one or both of the households are employed. As the income of the husband increases, so does the income of the family, which in turn increases the demand for children. As both men and women participate in childbirth, an increase in expected income will increase the cost of having children and have an impact on child demand. Increasing wages in families where both men and women are employed increases the value of leisure and working hours, thereby increasing the opportunity cost of children. It causes a decrease in the size of the family. Fertility decreases during periods of economic growth when a working woman is abundant. He found that when women worked long hours in their lives, increased the average age at first birth and decreased the time interval between births. It is further said that the mother's employability indirectly affects the daughter's fertility. This is because the daughters of working mothers are also more inclined towards job opportunities. Ermisch believes that if the economic situation changes, the expected number of children in the family can change.

Under this theory of A. Romanic, he explains that after world war II, the difference in birth rates between regions decreased. This is due to the declining influence of ethnic, linguistic, and religious factors. There is still a difference in the birth rate due to the level of education and the participation of the workforce. He further points out that the number of children expecting a young couple has dropped significantly. This is the result of changes in the role of women, changes in the status of children, increased use of birth control methods, and family planning. Decreased marriage and increased divorce rates are also cited as major factors in declining fertility. The marriage rate had dropped for those who aged under 35. Access to the workforce is minimal during periods of economic slowdown and rising inflation. Therefore, it has been found that marriages and childbirths are postponed and small families are formed.

The study of Nathan Keyfitz looked at how factors such as abortion and birth control affect birth rates. He proposed that a model that suggests that abortion does not prevent the birth of a population. It has the effect of reducing the time of a woman's next pregnancy. Women who use birth control methods are more likely to have all their children within a few years of their childbearing period. His model showed that older women tended to use birth control before younger women.

Moore (1997), found a relationship between ethnic groups and family size and explained that in Britain, there was a significant difference between the sizes of a family of Asians and the Blacks. The culture of the country from which they come from, and the age and sex distribution identified as the reasons for that. Blaney associated high fertility rates with poverty, low levels of education, high child mortality rates, less reproductive health services, and contraceptive prevalence rates while low fertility rates were associated with increased living standards, per capita income, life expectancy, level of education, and female employment. Ominde and Ejiogu (1972) stated that fertility differs with change in the age of marriage, the number of marriages, prevalence of polygamy, divorce and widow rates, prolonged lactation, unhealthily life, and malnutrition. In 2017, Sarvestani, Khoo, Malek, Yasin, and Ahamadi found that there was no difference between the expected number of children born to urban and rural married women while also revealing that female authority and income affect the number of women expecting children. The SPSS software is the main tool of this investigation and the Poison regression analysis method is used to predict the expected number of children in a married woman.

Arthur in 2005 found that factors such as family culture, family income, residence, family health, educational background, religion, and length of service influence family size. In 2018 Dana identified that sociological factors such as age at first cohabitation, education level of husband and wife, religion, place of residence, wealth, marital status, region, contraceptive methods, and working status of women affect fertility using the binary logistic regression model. Kandari (2007) explained that factors such as the respondent's level of education, occupation, age of marriage, socioeconomic status, and type of marriage have significant negative impacts on fertility and the main objective of his study was achieved using the multivariate regression model. Furthermore, he used descriptive and inferential statistical methods, the t-test method, and the Pearson correlation method for achieved specific objectives. Shirahase (2000), noted that the increase in women's participation in higher education has led to a decline in the fertility rate. The proportional hazard rate or cox regression analysis was used for the analysis of his survey. Four hypotheses have been tested for this study. First hypothesis about the family background, the second hypothesis about the educational background, the third hypothesis about the labor market, and the fourth hypothesis about the age of degree coexistence to illustrate trends in the assessment of the increase in women with higher education. Dibaba and Mitike (2016), identified that the level of education, age of marriage, and knowledge about family planning affect the family size. Women's employability, using family planning methods, level of schooling, and age of first marriage directly influences the decrease in fertility rate as viewed by Narayan (2006).

Uddin, Bhuyan, and Islam revealed that family size has a positive relationship with age. Hakim and Mahmood (1994), pointed out that the age and age of marriage also has a significant impact on fertility, and bivariate and multivariate analysis methods have been used to identify the impact of demographic and socioeconomic factors on women's fertility for his study. Howe, Westhoff, Vessey, and Yeates (1985) stated that the factors such as weight, height, or Quetelet's index did not show a significant correlation with fertility and that the fertility of women who get married at the age of 20 years and above is higher than that of women who get married before the age of 20 years; the fertility of women who get married after the age of 20 is relatively low. Sear, Mace, and Gregor discovered that there was no difference in the fertility rates between women who started reproduction at earlier stages and women who started later and also explained that there is a notable positive correlation between weight hemoglobin and fertility rate.

Many surveys have been conducted and multiple descriptive researches have been done related to this topic all over the world. Yet it is in contrast that only a very limited number of such researches related to this phenomenon are found in Sri Lanka. 
Neither have any sociological factors been explored to determine the number of children in households in the Colombo district of Sri Lanka. Most explorers focus on a limited number of sociological factors. As such, this exploration focuses on factors that others ignore and pay little attention to physical activity, fast food habits, government's procedure about fertility, chronic diseases, beauty cultural activities, information on how children were born, and how childbirth took place.

\section{MATERIALS AND METHODS}

This research was focused on the number of child-births in a Sri Lankan family and to identify its relationship with the demographic, socio-economic, and cultural factors. To achieve the above objective, structured questionnaires and telephone conversations were used to collect primary data while government-issued statistical data (Department of Census and Statistics), website statistics, journal information, and research articles were used to collect secondary data.

The total number of families in the Colombo district, 562550 (Census of Population and Housing-2012), was used as the population in this study. According to 2016 Demographic and Health Survey Statistics, Colombo, Gampaha and Ratnapura showed the lowest fertility rate and its value was 1.8. That is, the average number of children per household in these cities was around two. The Colombo district was selected for this study because of its low birth rate despite many health facilities, infrastructure, and other facilities.

A sample of 350 households was used for this study. This sample size was selected based on the cluster sampling method. A multi-stage cluster sampling technique was used for this research. Colombo District was selected for this survey and it was first divided into Divisional Secretariats. There are 13 Divisional Secretariat divisions in the Colombo District out of which the Colombo, Seethawaka, and Kesbewa Divisional Secretariats were randomly selected. Thereafter, two Grama Niladhari Divisions were selected for the survey from each Divisional Secretariat Division. These were Grandpass South, Maligawatta East, Suduwella, Nampamunuwa, and Wewala East. These Grama Niladhari Divisions were also selected at random. Finally, the number of families required for the sample was selected from the Grama Niladhari Divisions in proportion to the total number of families in each Grama Niladhari Division in the population.

Figure 1 shows the conceptual framework of this study. This study was carried out with 35 independents variables. These variables consist of 31 categorical variables and four continuous variables.

The study considers family size as the dependent variable. According to Demographic and Health Survey (2016) data, Kandy showed the highest fertility rate in 2016 and its value was 2.6. A survey of 50 samples from the Kandy district confirmed that the current average number of children in a household is three. Based on that value, the dependent variable was measured. Accordingly, households with total children ever born numbering less than three were identified as small families and those with total children ever born greater than or equal to three were identified as big families. Hence, small family coded as zero and big family coded as one.

Figure 1: Conceptual Framework

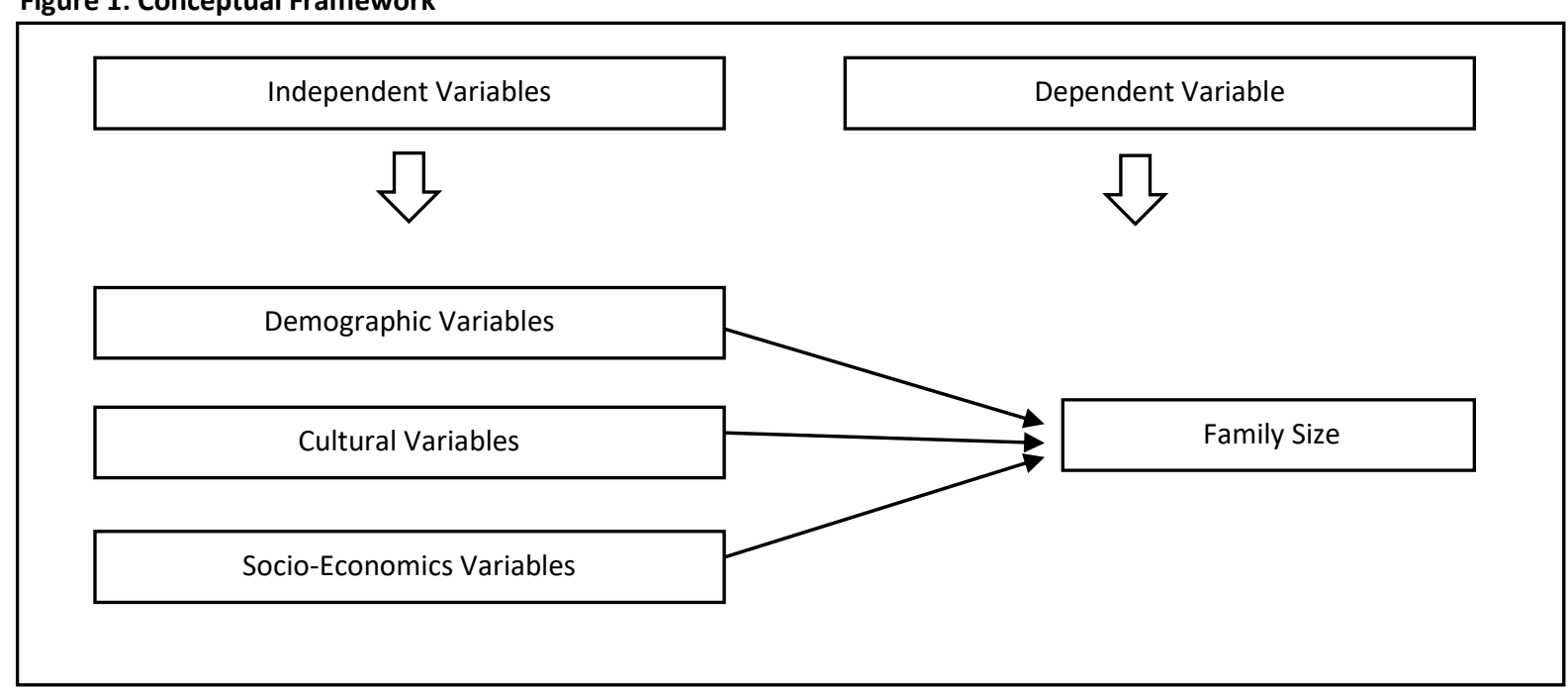

Source: Sample Survey 2020

Note:

- Variables of age, age of marriage, contraceptive method, age of first birth, natural abortion, drinking alcohol, the satisfaction of children, engage physical activity, engaged physical activity, balanced diet, chronic disease of wife, chronic disease of husband, exterior image, the desired number of children, partner died or not, partner daily come or not, satisfaction at home, likes children-wife, likes children-husband, divorce, fast food, smoking cigarette, beauty cultural method and caesarian categorized as demographic variables
- Variables of race and religion are categorized as cultural variables.

- Variables of the level of education, Women's employability, living sector, sufficient income, spends large proportion of income for children, impact of immigration, possibility of child care, monthly income, and awareness of family planning categorized as socioeconomics variables.

\section{Hypothesis}

The following hypotheses were developed by considering the conceptual framework for research analysis. 
$\mathrm{H} 1$ : There is a relationship between demographic variables on family size.

$\mathrm{H} 2$ : There is a relationship between cultural variables on family size.

H3: There is a relationship between socioeconomic variables on family size.

\section{RESULTS AND DISCUSSION}

The descriptive statistics of this study were represented by using table 1 .

Table 1: Descriptive Statistics

\begin{tabular}{|c|c|c|}
\hline Variable & Category & Proportion \\
\hline \multirow[t]{3}{*}{ Race } & Sinhala & $84.19 \%$ \\
\hline & Muslim & $9.19 \%$ \\
\hline & Tamil & $6.62 \%$ \\
\hline \multirow[t]{3}{*}{ Living Sector } & Rural & $22.43 \%$ \\
\hline & Semi-Urban & $44.12 \%$ \\
\hline & Urban & $33.46 \%$ \\
\hline \multirow[t]{2}{*}{ Women's Employability } & Employability & $52.57 \%$ \\
\hline & Unemployability & $47.43 \%$ \\
\hline \multirow[t]{5}{*}{ Level of Education } & Above Advanced Level & $21.32 \%$ \\
\hline & Up to Advanced Level & $34.93 \%$ \\
\hline & Up to Ordinary Level & $34.56 \%$ \\
\hline & Up to Scholarship & $8.46 \%$ \\
\hline & No Formal Education & $0.74 \%$ \\
\hline \multirow[t]{2}{*}{ Use of Contraceptive Methods } & Yes & $60.29 \%$ \\
\hline & No & $39.71 \%$ \\
\hline \multirow[t]{2}{*}{ Faced Natural Abortion } & Yes & $17.65 \%$ \\
\hline & No & $82.35 \%$ \\
\hline \multirow[t]{2}{*}{ Faced Caesarian } & Yes & $44.49 \%$ \\
\hline & No & $55.51 \%$ \\
\hline \multirow[t]{2}{*}{ Immigration } & Yes & $40.81 \%$ \\
\hline & No & $59.19 \%$ \\
\hline
\end{tabular}

Source: Sample Survey 2020

Under the variable of race in this study majority of respondents were Sinhala and it shows 84 percent in the whole sample and 44 percent households from the selected sample include in semi-urban areas. More than 50 percent of women were currently employed. Its value was approximately equal to 53 percent. Most women have completed their education up Advanced Level and Ordinary Level and it was about 35 percent as a percentage. Approximately two-thirds of the women who were selected for this sample used birth control methods. According to the contraceptive prevalence rate (\%) 2020 country ranks, Sri Lanka was ranked 46th with a contraceptive prevalence rate of 61.7 percent (Source: CIA World Factbook). Similarly, conforming to contraceptive prevalence, Sri Lanka is ranked 16th in the Asian country rankings (Source: UNICEF's State of the World's Children and Figure 2: Size of family Social Science (SPSS) software and the Binary Logistic Regression model was used to achieve the main objective: identification of factors that influencing Sri Lankan family size. In addition, Correlation analysis, Chi-Squared test, Independent sample t-test, and ANOVA test were used to identify the association between variables.
The gathered data was analyzed using Statistical Package for
Childinfo, United Nations Population Division's World Contraceptive Use, Household surveys including Demographic and Health Surveys and Multiple Indicator Cluster Surveys). About 18 percent of women in Colombo district faced natural abortion and about 44 percent of women faced surgery of caesarian as the mode of delivery. When looking at an urban area like Colombo, one can see that some residents are permanent and someone is not. Residence in this area is subject to change frequently. About 59 percent of these households were permanent residence of Colombo and the remaining 41 percent were immigrants from other areas.

The main purpose of this study is to identify the factors that influence the Sri Lankan family size. The size of a family is considered the dependent variable.

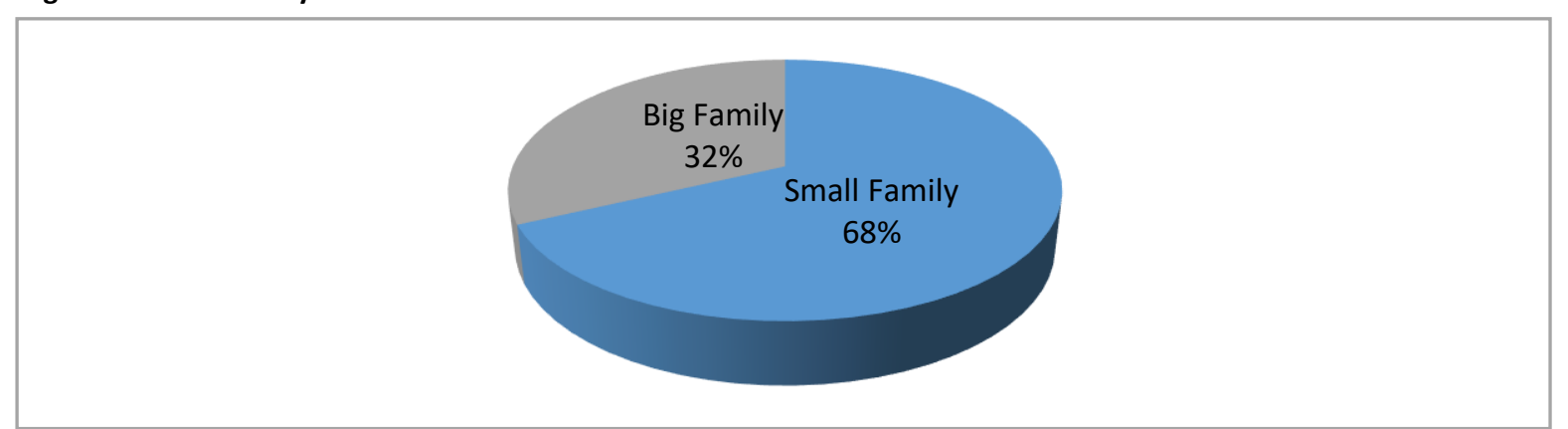

Source: Sample Survey 2020

Figure 2 represents the percentage of live births of women selected in the sample. The majority of households in that sample were small families, which is 68 percent of the total. About 32 percent of households were big families. It is less 
than half the percentage of households which were small families. This figure is a clear indication that a contemporary household has less than three children.

According to the contraceptive prevalence rate (\%) 2020 country ranks, Sri Lanka was ranked 46th with a contraceptive prevalence rate of 61.7 percent (Source: CIA World Factbook). Similarly, conforming to contraceptive prevalence, Sri Lanka is ranked 16th in the Asian country rankings (Source: UNICEF's State of the World's Children and Child info, United Nations Population Division's World Contraceptive Use, Household surveys including Demographic and Health Surveys and Multiple Indicator Cluster Surveys).

The relationship between contraceptive methods and the number of child-births in a household is represented in figure 3 .

Figure 3: Size of Family Based on Contraceptive Method

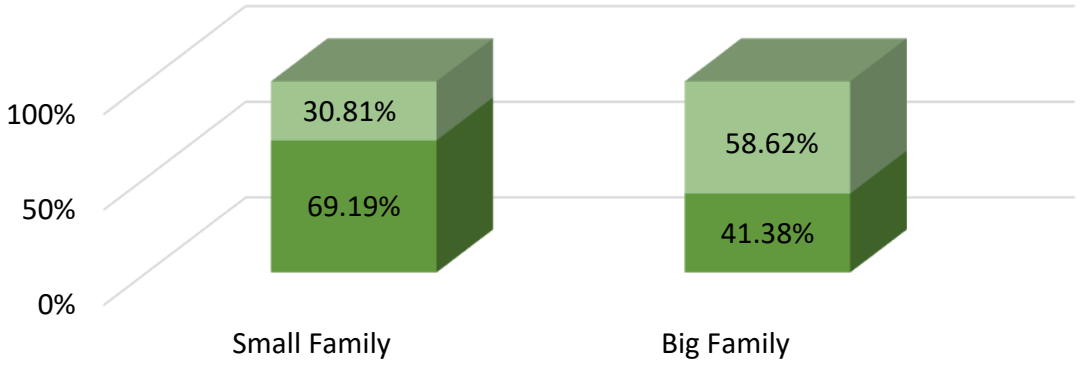

Total Children Ever Born

Yes No

Source: Sample Survey 2020

According to figure 3 , about 69 percent of women with small families were using contraceptive methods while about 31 percent didn't. Among women who had big families, 59 percent of women were not using contraceptive methods which the leftover 41 percent did use. This figure shows that women who do not control births have more children than women who control births so far.

Religion is one of the most influential factors related to the size of a family. Figure 4 shows how religion relates to the number of children in a household.

Figure 4: Size of Family Based on Religion

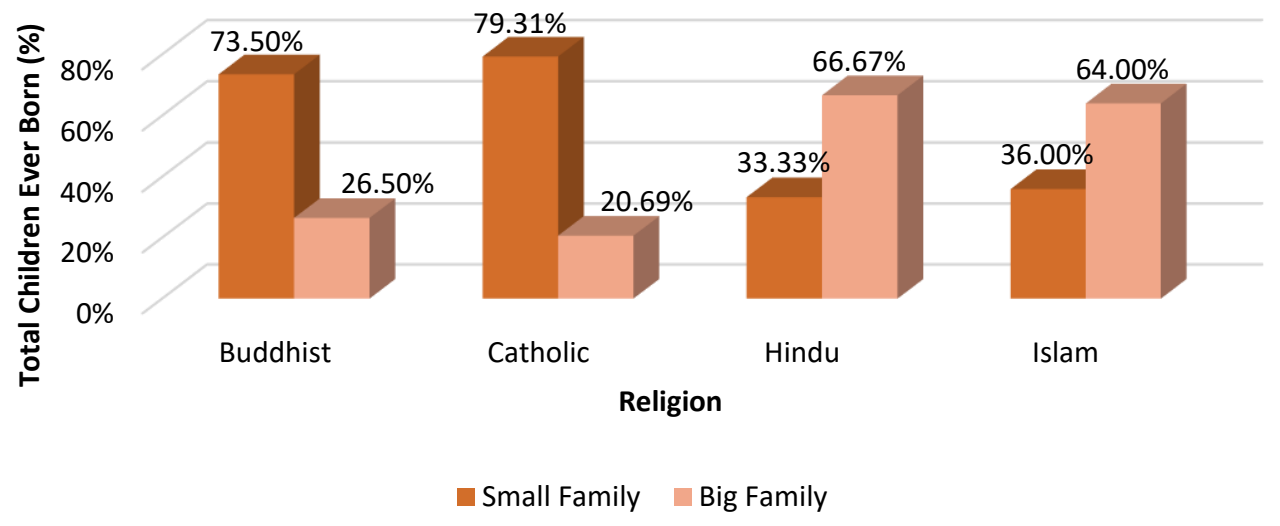

Source: Sample Survey 2020

According to figure 4, 74 percent of Buddhists had small families and only 27 percent had big families. In this regard, Catholics were similar to Buddhists with 79 percent of women having small families and 21 percent having big families. Hindu and Islam respondents had more children than those from the other religions. Hindu and Islam women with big families were 67 percent and 64 percent respectively.
Hindu and Islam women who had small families were 33 percent and 36 percent respectively.

The level of education of a woman is a factor that directly affects the number of children in a household. The relationship between education and the number of children in a household is shown in figure 5 . 
Figure 5: Size of Family Based on the Level of Education

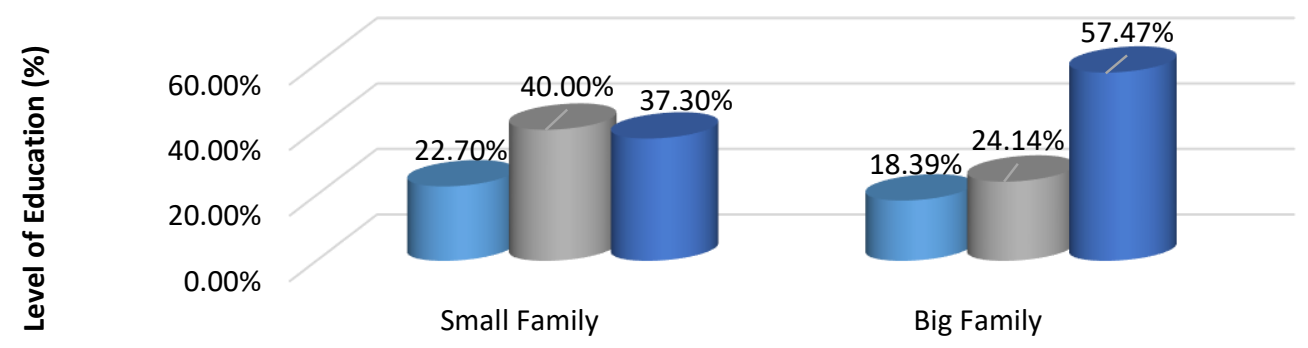

Total Children Ever Born

above $\mathrm{A} / \mathrm{L} \quad \mathrm{Up}$ to $\mathrm{A} / \mathrm{L} \quad$ Up to $\mathrm{O} / \mathrm{L}$

Source: Sample Survey 2020

According to figure 5, about 23 percent of households with less than three children were women involved in higher education while about 40 percent of women were educated up to advanced level. 37 percent of women had education up to or below the ordinary level. On the other hand, the majority of women in households with three or more children were educated up to or below the ordinary level with a percentage nearing 58 . Women who had more children were revealed to have limited exposure to higher education and advanced level; only around 18 percent and 24 percent respectively. This depicts that women with higher exposure to Table 2: Size of Family Based on Age of Marriage

\begin{tabular}{lrr}
\hline Age of Marriage & Small Family & Big Family \\
\hline Below 25 & $38.38 \%$ & $71.26 \%$ \\
\hline $\mathbf{2 5 - 2 7}$ & $25.41 \%$ & $16.09 \%$ \\
\hline Above 27 & $36.22 \%$ & $12.64 \%$ \\
\hline
\end{tabular}

Source: Sample Survey 2020

Table 2 represents the relationship between the number of children and a woman's age of marriage. Most women who had big families were married before the age of 25 . It is more than two-thirds of the whole sample and 71 percent as a percentage. In contrast, only around 16 percent of the women who had big families married at the ages between 25 and 27 while 13 percent of them married at or after the age of 27.

\section{Data Analysis}

The data were analyzed using the binary logistic regression method in the Statistical Package for Social Science (SPSS) software. The purpose of the binary logistic regression was to establish the relationship between the number of childbirths and what the influential factors are in a Sri Lankan family.

Here, we firstly identified the independent variables which were associated with the dependent variable named total children ever born. Then variables that were not related to the dependent variables were excluded from the model. There were 35 independent variables were studied for this survey. And using the chi-square test and independent-sample t-test, identified 20 independent variables that were associated with the dependent variable total children ever born, among those 35 variables. The set of independent variables consist of 17 categorical variables and three continuous variables. These variables were race, religion, level of education have a smaller number of children compared to the women who are less inclined to education.

A woman's marital age is another important factor that directly impacts her birth rate. A contemporary woman's marital age is considerably late for various reasons. Previous researches revealed that as a woman's age of marriage increases, the number of children decreases. Table 2 shows the impact of women's age of marriage on the number of children.

education, women's employability, living sector, the satisfaction of children, sufficient income, cost of raising children, engage physical activity, engaging in physical activity, balanced diet, drinking alcohol. contraceptive methods, chronic disease of wife, exterior image, the desired number of children, age, age of marriage, age of first birth, and natural abortion. These variables were used for further analysis. The second step identified there was no association between independent variables. In other words, checked multicollinearity. Here, any independent variables which were related to each other variables were excluded from the model. Chi-square test, ANOVA test, and correlation test were used to identify the relationship between independent variables. Through this test, select six independent variables which were not associated with each other. These were women's employability, contraceptive methods, the satisfaction of children, drinking alcohol, age of marriage, and natural abortion. These six variables were consisting of five categorical variables and one continuous variable. Binary logistic regression model run with these six variables.

Then fitted the several models (one-variable model, twovariable model, and three-variable model) and identified the best-fitted model based on the $\mathrm{G}^{2}$ value. Lastly, using Hosmer-Lemeshow test checked the goodness of fit of the bestfitted model. 
Table 3: Model with Age of Marriage, Contraceptive Method and Natural Abortion

\begin{tabular}{|c|c|c|c|c|c|c|c|}
\hline Parameter & B & S.E. & Wald & df & Sig. & $\operatorname{Exp}(B)$ & $\mathbf{G}^{2}$ \\
\hline Age of Marriage & -0.161 & 0.044 & 13.188 & 1 & 0.000 & 0.851 & \multirow{4}{*}{39.171} \\
\hline $\begin{array}{l}\text { Contraceptive } \\
\text { Method }\end{array}$ & 1.106 & 0.282 & 15.363 & 1 & 0.000 & 3.022 & \\
\hline Natural Abortion & 0.894 & 0.420 & 4.538 & 1 & 0.033 & 2.444 & \\
\hline Constant & 1.919 & 1.150 & 2.783 & 1 & 0.095 & 6.812 & \\
\hline
\end{tabular}

Source: Sample Survey 2020

logit $P(x)=\beta 0+\beta 1$ Age of Marriage $+\beta 2$ Contraceptive Method $+\beta 3$ Natural Abortion

According to the table 3 , age of marriage, contraceptive method and natural abortion can be taken as significant var-

logit $P(x)=1.919-0.161$ Age of Marriage +1.106 Contraceptive Method +0.894 Natural Abortion iables for the model. Hence, their $p$-values were less than 0.05 significant level.

Table 4: Hosmer and Lemeshow Test

\begin{tabular}{llc}
\hline Chi-Square & Df & Sig. \\
\hline 7.522 & 8 & 0.481 \\
\hline
\end{tabular}

Source: Sample Survey 2020

According to the Hosmer and Lemeshow test, the P-value is greater than the significant value of 0.05 . Thus, there is not enough evidence to reject the null hypothesis. As such, the conclusion was that the model is adequately fitted.

Therefore, best fitted model can be written as follows.

logit $P(x)=1.919-0.161$ Age of Marriage +1.106 Contraceptive Method +0.894 Natural Abortion

When all other factors are constant, if the variable 'age of marriage' is postponed by one year, then the chance of having a small family is 85.3 percent. When all other factors are constant, women who do not use contraceptive methods have a 95.37 percent chance of having a big family compared to the women who do use contraceptive methods. Similarly, when all other factors are constant, women who have not faced at least one abortion have a 94.34 percent chance to have a big family compared to the women who have faced at least one abortion.

In 2018 Dana pointed out that there is a relationship between family size and the use of contraceptive methods. Kandari (2007) and Hakim (1994) stated that women's age of marriage is the most significant variable with the number of children in a household. And Dibaba and Milike (2016) also found it is the most important variable that affects family size. This study identified women's age of marriage and use of contraceptive methods were significant variables that affect the Sri Lankan family size. Uddin, Bhuyan, and Islam (2011) and Shirahase (2000) identified women's level of education influence the size of the family. In 2005 Arthur said that the educational background of women and family income major determinants affect family size. In 2000 Brewster and Rindfuss 2000 and 1986 Lehrer and Nerlove found that women's employability negatively affects fertility. But in this study, these variables do not represent the significant relationship with Sri Lankan family size. And this study also found that women who faced incidents of natural abortions were influenced by the number of children in a Sri Lankan family.

\section{CONCLUSION}

The marital age of a woman was identified as a major factor influencing the number of children in a household. It was revealed that the number of children in a household decreases as a woman's age of marriage is postponed. Many women in Sri Lanka today tend to get married after the age of 25. Multiple factors influence women to have such delayed marriages such as their fervent pursuit of further education and employment. As a result, most women tend to stay away from marriage until they reach a certain position in their life, extending the contemporary age of marriage in Sri Lanka to over 27 years.

Another identified major factor was the increasing use of contraceptive methods by women. That is, women who use contraceptive methods have two or a smaller number of children than women who do not. Today, Sri Lanka is one of the leading countries in the world in the use of contraceptive methods. It is conceivable that women in today's society turn to birth control due to factors such as a busy life and stress due to women turning to employment. In addition, factors such as the inability to care for children and the lack of adequate income may also be causes.

The other factor that caused a decline in the number of children in a household was the increase of natural abortions. Today's women have a higher chance of facing natural abortions which have become a glaring problem in the present society. These natural abortions may be caused by the busyness of women, accumulated stress, poor food habits, and other negative factors. The number of children of a woman who has faced at least one abortion shows a significant decrease compared to women who have not faced any.

Religion is another important factor that affects family size. Islam women have more children compared to Buddhist and Catholic women. Hindu women also have comparatively more children. This consolidates that religion is a significant variable that affects the size of a Sri Lankan family.

The negative relationship between a woman's level of education and total children ever born is also worth note. This declares that if a woman's level of education is increased, the number of childbirths in a household is decreased. In the present, a majority of women spend more time on education which leads to the creation of smaller families.

This research provides important recommendations for government and policymakers. Among them, the majority point is the education system in Sri Lanka. Students seeking higher education in Sri Lanka have to wait longer to complete their higher education. As a result, women are around 27 years old when they complete their higher education. Therefore, if this pattern of education is changed and higher education is completed within five years, it can to some extent reduce the problem of the age of marriage.

The widespread use of contraceptive methods increases the risk of side effects. It would be appropriate to inform women resorting to these methods of the adverse effects they may 
face through methods of health promotion and health workshops.

Natural abortions can also be minimized with the help of family health officers. Married women will thus be exposed to knowledge that will help them attain physical wellbeing as well as mental serenity. For example, motivation to meditate or do yoga practices, abstinence from fast food, and following a more nutritious diet as well as recommendations on the amount of safe physical activity for women.

\section{REFERENCES}

Al Kandari, Y. Y. (2007). Fertility and its relationship with sociocultura factors in Kuwaiti society. EMHJ-Eastern Mediterranean Health Journal, 13 (6), 1364-1371, 2007.

Arthur, J. L. (2005). Family size and it" s socio-economic implications in the Sunyani Municipality of the Brong Ahafo region of Ghana. WestAfrica. Center for Development Studies, Ghana. Unpublished.

Asadi Sarvestani, K., Leng Khoo, S., Malina Malek, N., Mat Yasin, S., \& Ahmadi, A. (2017). Factors Influencing the Desired Number of Children Among Married Women in the Reproductive Age and its Implications for Policy-Making. Women's Health Bulletin, 4(2), 1-6.

Becker, G.S., 1960: An economic analysis of fertility - Demographic and economic change in developed countries, Princeton: Princeton University Press, NBER, NJ

Blaney H. C. (1992), III World Scientists' Warning to Humanity, a statement signed by 1600 scientists, Union of Concerned Scientists,

Brewster, K.L. and Rindfuss, R.R., 2000: Fertility and women's employment in industrialized nations. In: Annual Review of Sociology, Vol. 26, pp. 271-296. DOI: http://dx.doi.org/10.1146/annurev.soc.26.1.271

Census of Population and Housing-2011. (n.d.). Retrieved from www.statistics.gov.lk: http://www.statistics.gov.lk/PopHouSat/CPH2011/index.php?fileName $=\mathrm{H} 11 \& \mathrm{gp}=$ Activities $\& \mathrm{tp} \mathrm{l}=3$

Cleland, J., \& Wilson, C. (1987). Demand theories of the fertility transition: An iconoclastic view. Population Studies, 41(1), 5-30.

Contraceptive prevelence rate (\%) 2020 country comparisons. (n.d.). Retrieved August 02, 2020, from www.photius.com: https://photius.com/rankings/2020/population/contraceptive_prevalence_rate_2020_0.html

Dana, D. D. (2018). Binary logistic regression analysis of identifying demographic, socioeconomic, and cultural factors that affect fertility among women of childbearing age in Ethiopia. Science Journal of Applied Mathematics and Statistics, 6(3), 65.

Dibaba, B., \& Mitike, G. (2016). Factors influencing desired family size among residents of Assela Town. J Women's Health Care, 5(6), 1-8.

Fertility levels, differentials, and trends- Department of Census and Statistics. (n.d.). Retrieved August 03, 2020, from www.statistics.gov.lk: http://www.statistics.gov.lk/Resource/en/Health/DemographicAndHealthSurvey Report-2016-Chapter4.pdf

Hakim, A., \& Mahmood, N. (1994). Factors Affecting Fertility in Pakistan [with Comments]. The Pakistan Development Review, 33(4), 685-709.

Harbour, C. (2011). Normative influence and desired family size among young people in rural Egypt. Studies in family planning, 42(2), 107116

Howe, G., Westhoff, C., Vessey, M., \& Yeates, D. (1985). Effects of age, cigarette smoking, and other factors on fertility: findings in a large prospective study. Br Med J (Clin Res Ed), 290(6483), 1697-1700.

https://uwaterloo.ca/waterloo-research-institute-in-insurance-securitiesand-quantitative-finance/sites/ca.waterloo-research-institute-in-insurance-securities-and-quantitative-finance/files/uploads/files/01-06.pdf

Lehrer, E. and Nerlove, M., 1986: Female labor force behavior and fertility in the United States. In: Annual Review of Sociology, Vol. 12, pp. 181-204, available at: http://www.jstor.org/stable/2083200

Lerner, R. M., \& Spanier, G. B. (1978). A dynamic interactional view of child and family development. Child influences on marital and family interaction: A life-span perspective, 1-22.

Moore, S. (1997) Sociology Alive, Scotprint Ltd, Musselburgh, Great Britain

Narayan, P.K., 2006: Determinants of female fertility in Taiwan, 19662001: Empirical evidence from cointegration and variance decomposition analysis. In: Asian Economic Journal, Vol. 20, Issue 4, pp. 393 407. DOI:
Noller, P., \& Fitzpatrick, M. A. (1993). Communication in family relationships. Englewood Cliffs, NJ: Prentice-Hall

Ominde, S.H., and C. N. Ejiogu. 1972, Population Growth and Economic Development in Africa, Population Council, New York, U. S. A.

Sear, R., Mace, R., \& McGregor, I. A. (2003). A life history approach to fertility rates in the rural Gambia: evidence for trade-offs or phenotypic correlations? In The biodemography of human reproduction and fertility (pp. 135-160). Springer, Boston, MA.

Shirahase, S. (2000). Women's increased higher education and the declining fertility rate in Japan. Review of Population and Social Policy, 9, 47-63.

Sri Lanka Fertility Rate 1950-2020 | Macro Trends. (n.d.). Retrieved August 02, 2020, from www.macrotrends.net/: https://www.macrotrends.net/countries/LKA/srilanka/fertility-rat

Sriram, R. (1993). Family studies in India: Appraisal and new directions. Human development and family studies in India: An agenda for research and policy, 122-128.

TOTAL FERTILITY RATE. (n.d.). Retrieved August 03, 2020, from www.doh.state.nj.us: $\quad$ https://www-doh.state.nj.us/dohshad/view/sharedstatic/TotalFertilityRate.pdf

Uddin, M., Bhuyan, K. C., \& Islam, S. S. (2011). Determinants of desired family size and children ever born in Bangladesh. 
